\title{
The CAG role in graduate education
}

\author{
Desmond Leddin M B FRCPC \\ Chair, CAG Education Committee
}



En français voir page 218
C entral goals for the $C$ anadian A ssociation of Gastroenterology (CAG) and the Canadian Digestive $\mathrm{H}$ ealth Foundatin (CDHF) are those of maintaining and increasing the 'bolus' of researchers and clinicians that enter the gastroenterology (GI) stream. This affords the required basic research base and clinical mass to accommodate future requirements on the health care system with respect to GI. To meet the clinical demand for $\mathrm{GI}$ services, it is necessary that an appropriate number of residents choose GI as a subspecialty, and that those who choose $\mathrm{GI}$ are appropriately trained.

The CA Education committee plays a role in both of these areas.

A ccording to the $C$ anadian Resident $M$ atching Service, approximately $1400 \mathrm{C}$ anadian medical students graduate each year. A nother 700 independent students, including former graduates of $\mathrm{C}$ anadian medical schools, A merican students and graduates of international medical schools, compete for 200 positions in the second iteration of the match. However, in 2002 only 163 graduating students chose internal medicine as a career. It is from this group that new gastroenterologists will emerge.

Residents completing their third year of internal medicine training can choose a number of directions. They can continue on and graduate as general internists. This role has al ways been important and may become even more important in the near future, with the move toward integrated primary and secondary care. They can also choose from one of the 22 subspecialty programs on offer. Clearly, if GI is to maintain its ranks, we have to be competitive for a relatively small number of graduates.

The CA G has established the Scholars Program to attract residents into GI. Drs Bob Bailey and Richard Fedorak initiated this in 2001, now chaired by Dr Jamie G regor (U niversity of W estern 0 ntario, London, 0 ntario). Each teaching university is asked to nominate up to two medical residents to attend the program. The program allows students an opportunity to meet and interact with a number of role models from community, hospitalbased, university and nonuniversity, practices. The program has been very successful in enlightening students who are leaning toward $\mathrm{Gl}$, and reassuring them that their choice is a good one.
Once the residents are committed to GI, CA G also plays a role. CA provides a three-day course ( $G$ astroenterology Residents in Training Program - GRIT) before each C anadian Digestive Diseases Week conference. This is now in its 11th year and has become a highlight of CA G 's education efforts. $D r$ Ron Bridges (Calgary, A lberta), who works with a group of very talented educators and scientists, chairs it. The residents have to submit a work of value to gain admission. It consists of a series of events, some are didactic, most are highly interactive and innovative. Residents are provided with an agenda regarding key GI issues, an opportunity to present their work as well as interact with peers in small group sessions and an opportunity to connect with their colleagues across the country. It is an intensive course which make the $08 \mathrm{~h} 00-17 \mathrm{~h} 00$ schedule of the main meeting appear relaxed. For those of us fortunate to have been invited to teach at this meeting it is an experience not to be forgotten for both the quality of the science and education and the general sense of energy that these extremely talented residents bring to the meeting. My personal favourite would have to be the GI residents from Q uebec presenting their analysis of a clinicopathological conference on W hipple's disease to the tune of "YMCA".

In addition to the annual meeting, the on-line interactive lecture series (www.cag-acg.org), and the liaison between the Royal College, the CA G, and the GI community (for section 1 accredited events) there are two specific educational programs which the CA G promotes. In 2002, it was brought to CA G's attention that some of the residency training programs were having difficulty in running basic and clinical science rounds. W ith the support and sponsorship of industry, a national videoconference round was established. Dr Dana Farina and Dr Janice Barkey chair this initiative. Each month residents go to their local videoconference site and are given an interactive presentation by a national expert on a selected topic. M ore details on this program can be found under the Education section of the CA G W eb site at www.cag-acg.org. This is the first year of the program and the feedback to date is very positive.

The role of CA G in graduate education is one of which the organization can justifiably feel proud.
A bbott Laboratories Ltd.
A straZeneca $C$ anada Inc.
A xcan Pharma Inc.
Janssen-0 rtho Inc. 


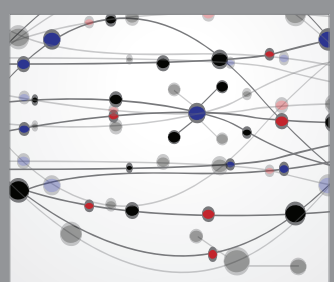

The Scientific World Journal
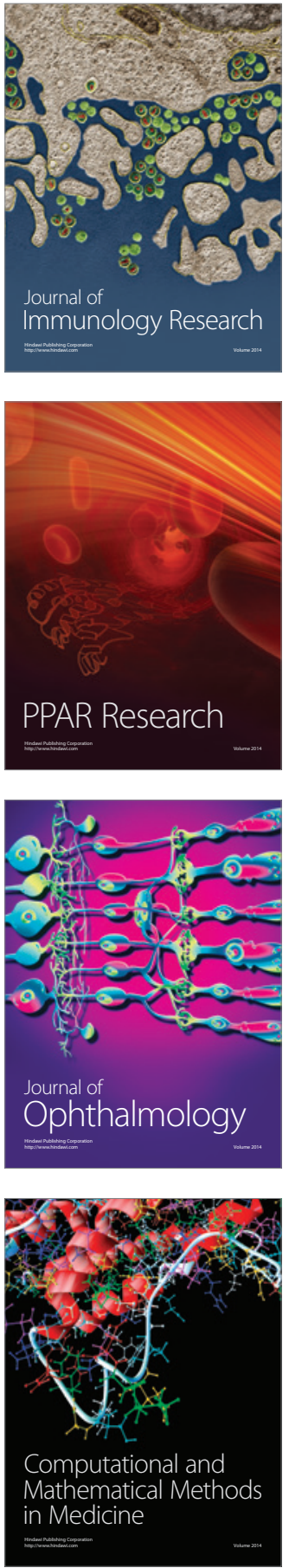

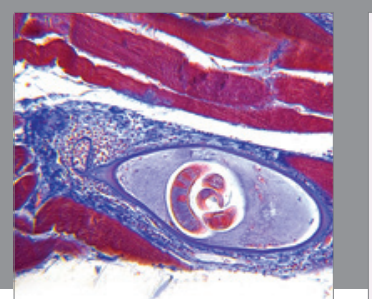

Gastroenterology Research and Practice

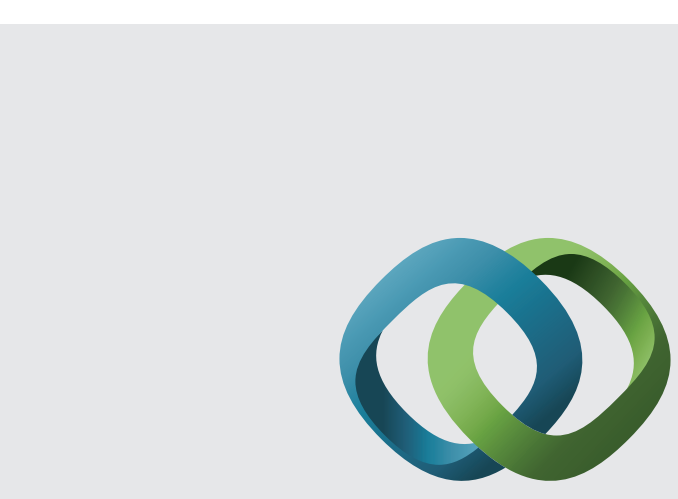

\section{Hindawi}

Submit your manuscripts at

http://www.hindawi.com

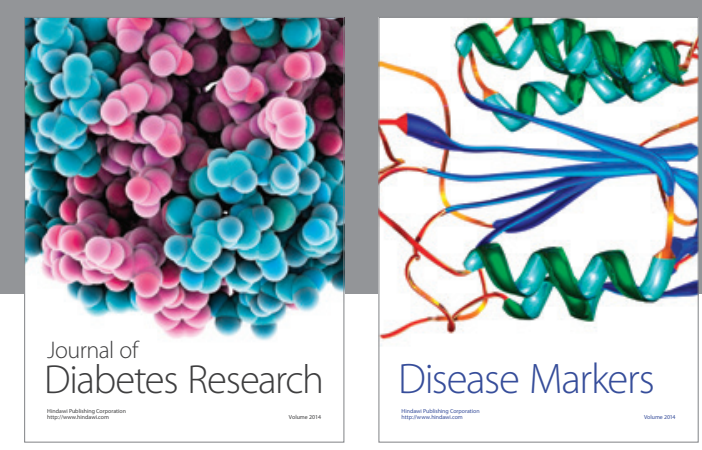

Disease Markers
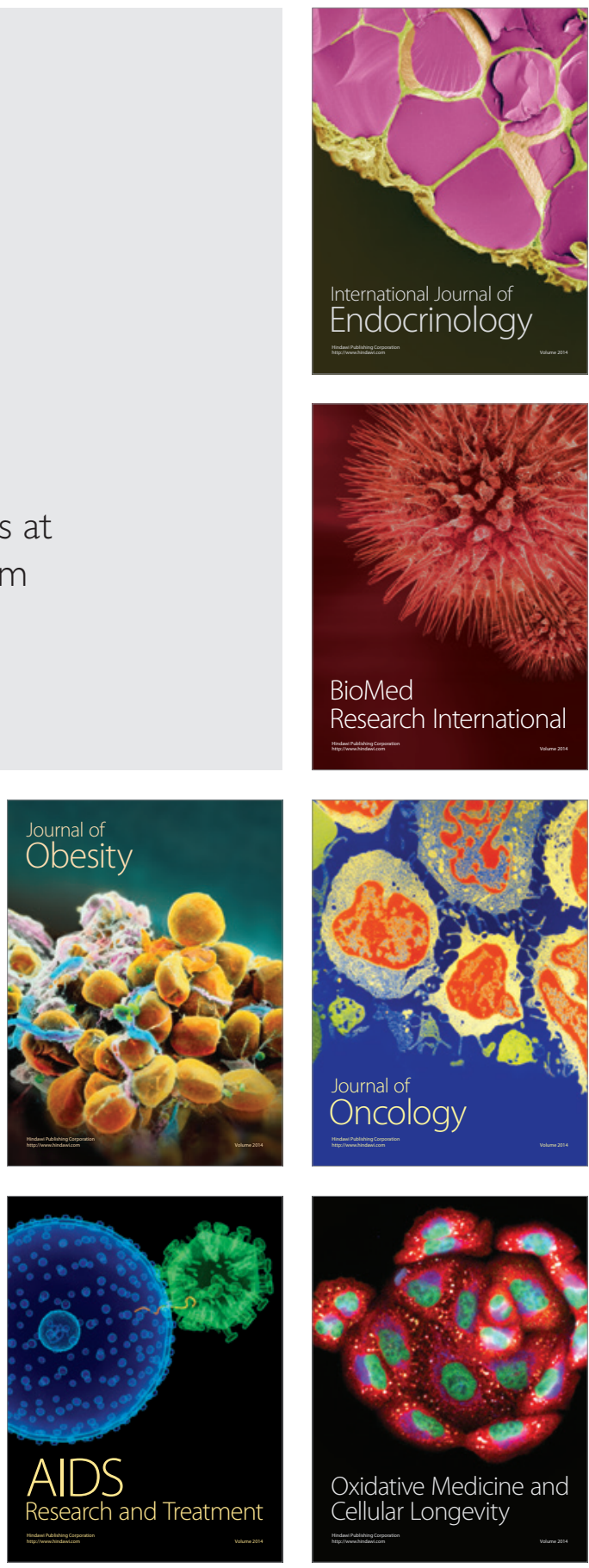